\title{
The Evolution of Filial Piety in Ancient China and Its Influence on Neighboring Countries: Taking the Classic of Filial Piety as the Chief Source
}

\author{
Miao Chungang \\ ${ }^{1}$ China University of Political Science and Law, Law school, Grade 2014, Ph. D Candidate, Beijing, China \\ Correspondence: Miao Chungang, Graduate School of China University of Political Science and Law, No. 25 \\ Xitucheng Road, Haidian District, 100088 Beijing, China. Tel: 86-150-1011-6106. E-mail: \\ sdulmiao0753@sina.com
}

Received: April 22, 2015 Accepted: May 11, 2015 Online Published: May 20, 2015

doi:10.5539/ass.v11n12p319 URL: http://dx.doi.org/10.5539/ass.v11n12p319

\begin{abstract}
Filial piety is a typical feature of Chinese civilization. Represented by the book of The Classic of Filial Piety, the filial culture in China experienced different periods of establishment, development and maturity. The pre-Qin period is the germination time for the filial culture, and the book of The Classic of Filial Piety, a systematic filial thought was formed in Warring States period. The rulers of Han dynasty drew hard lessons from Qin, which was ruined by its tyranny, and decided to govern the country with filial piety. During this period, Dong Zhongshu used Confucian classics to do judgments, preliminarily realized the legalization of Confucianism such as the filial piety. The formulation of the Tanglv Shuyi marks the full legalization of Confucianism, and filial piety was completely integrated into the legal norms. From Tang dynasty, most of the emperors in Chinese history all paid attention to The Classic of Filial Piety, even involved in the compilation of its explanatory notes, advocating to perform filial rule in the country. Since the Tang dynasty, with the strengthening of Chinese and foreign cultural exchanges, The Classic of Filial Piety and filial piety culture widely spread abroad. At the same time some neighboring areas such as Japan, the Korean peninsula and Vietnam was profoundly influenced by The Classic of Filial Piety and the filial piety culture.
\end{abstract}

Keywords: the classic of filial piety, filial piety, filial rule, cultural transmission

\section{Introduction}

Due to its peculiar charm, the ancient Chinese civilization not only affects the life of the Chinese people, but also has important influence on other Asian countries' civilization in history. The characteristics of Chinese civilization aroused the interests of many scholars at home and abroad. German philosopher Hegel had good evaluation on the characteristic of Chinese culture, saying that "China was purely constructed on the combination with morality, and the national characteristic is the objective family filial piety." (Hegel, 2006). In Chinese and western academic circles, the filial piety culture was generally acknowledged as the typical characteristics of the Chinese civilization. British philosopher Bertrand Russell was intensely curious about China's filial thought, and he pointed out that "filial piety is not exclusive to the Chinese, but a common phenomenon in the world in a certain cultural stage. Strangely, China still preserves the old habit when its culture has reached a relatively high level. Whereas in ancient Rome and Greek, which also pay attention to filial piety, family relationship gradually became loose with the development of civilization. But China is not the case."(Russell, 1996). It is true with the fact. With the development of Chinese civilization, the philosophy of filial piety and loyalty were combined and consolidated in the form of law, which promoted the continuation and development of filial piety. In a sense, Russell's confusion can be extended to the whole East Asian cultural circle, where filial piety is not dying with the development of civilization in South Korea, Japan and Vietnam. Thus the traditional filial piety has its reasonable aspect in history. Based on the interest in the idea of "filial piety", the research of this classic book of The Classic of Filial Piety becomes necessary. In history, this book is not only constantly legalized in Chinese history, but also widely spread to other Asian countries. From the perspective of the cultural heritage, the spread of The Classic of Filial Piety as well as the thought of "filial piety" has a profound significance to Asian cultural history. 


\section{The Classic of Filial Piety and Filial Piety in Chinese History}

\subsection{Filial Piety in Pre-Qin Period}

During the Pre-Qin Period, ancient civilization has come into being in China, including the filial culture that we are familiar with. In the process of history, the filial piety originally comes from human's worship for their ancestors. With the appearance of states, the filial concept of "to be kind to one's parents" gradually took shape. When it comes to the Western Zhou dynasty, the filial piety has become the core content in the country's religious belief and political system. Filial piety was officially conformed as a crucial part of "morality". In the spring and autumn period and the Warring States period, the compilation of The Classic of Filial Piety marked the preliminary complement of theorization of filial thought in the period before Qin dynasty.

\subsubsection{Filial Concept in Xia, Shang, Zhou Periods}

In the time of primitive clan society, the original concept of ancestor worship was formed based on the need of human's survival competition. The concept naturally evolved into concern and care for parents in reality. In Xia and Shang periods, the early concept of nation appeared. With the development of the concept of home and nation integration under patriarchal hierarchy system, rulers developed the thought of theocratic law. The monarchs of Xia and Shang dynasties claimed themselves to be the son of "God", on behalf of whom to rule the people, thus developing the thought of "mandate of heaven, scourge of heaven". Filial piety during this period was mainly in the form of ancestor worship and was deliberately reinforced by religious rites. With the demise of Shang dynasty, the thought of "mandate of heaven, scourge of heaven" underwent great impact, and the rulers of Western Zhou dynasty creatively put forward the idea of "God's will combined with good virtue". The rule of the Western Zhou dynasty implemented the system of enfeoffment on the basis of the genetic connection in reality, and patriarchal clan system in politics. The filial piety at that time made great development on the object of filial piety, both to living parents and his dead parents and ancestors. In accordance with the theocratic law at that time, the filial piety in Western Zhou dynasty served for the real regime and had strong patriarchal ethics. In the guidance of this thinking, the content of filial piety combined with ritual law system, emphasizing the patriarchal authority.

\subsubsection{Formation of Confucius Filial Piety in the Pre-Qin period}

With the "ritual collapse" in the Spring and Autumn period, tremendous changes took place in social, political and economic structures. Under this background, the filial piety maintaining the patriarchal hierarchy of Western Zhou dynasty had also been shaken, and the thought of theocratic law faced intense doubt. To rebuild social order, Confucius converted the filial concept of ancestor worship in Zhou dynasty into a kind of personal moral cultivation with filial piety to the living parents at its core, making the thought of filial piety popular among the public. Confucius's filial piety view has the following several distinctive features: first, the concept of filial piety has strong humanistic feelings, putting the real world demands at first place. Confucius advocated the concept that "failed to care about the living people, how can a person manage to respect the dead?" This kind of respectful attitude to ghosts satisfied people's inner demand in a turbulent period. Second, the content of filial concept became more rich, and the connotation of being filial to parents was extended from "the satisfaction of material life" to "all around satisfaction of material and spiritual life". Confucius said that "nowadays the one who can support his parents can be called filial, but dogs and horses can also support their parents. Without respect, how can we distinguish ourselves from animals?" The respect toward parents distinguishes people from animal instinct, satisfying parents' spiritual demands. Thirdly, filial piety is not blind obedience to parents' will. It is also filial behavior to point out parents' fault in an appropriate way when the parents are wrong indeed. Generally speaking, in a new social environment, Confucius tried to construct a new family relationship of "amiable father and filial children".

\subsubsection{Systematization of the Pre-Qin Confucian Filial Piety-The Classic of Filial Piety}

After continuous development of filial piety by Confucius and his disciples, systematic The Classic of Filial Piety appeared in the late Warring States. Because of historical reasons, from the pre-Qin dynasty to the Han dynasty, author's name could not be contained in a book. There are nine statements about the authors of The Classic of Filial Piety, which is said that the authors include Confucius, his students Mencius and so on. It is also difficult to make sure the time of the complement of the book. Structurally, The Classic of Filial Piety is divided into two volumes, including eighteen chapters and a total of 1903 words. However, in such little space, its content is extremely rich. To cater the debates of how to manage state affairs of Spring and Autumn period, the Classic of Filial Piety advocated "filial piety". In terms of content, it mainly consists of two parts: one is real connotation of filial morality of oneself, including the Common People Chapter, Jingxiao Chapter, Bereavement 
Chapter, and the other is about the "governing the country with filial concept", developed around the topics of how to support, direct and cultivate people with filial concept.

\subsection{The Classic of Filial Piety and Filial Piety Policy in the Han Dynasty}

The Han rulers spoke highly of The Classic of Filial Piety and tried to achieve the goal of "governing the country by filial piety". Emperor Wu in the Han Dynasty carried out a policy of proscribing all non-Confucian schools of thought and espousing Confucianism as the orthodox state ideology, and elevated the status of Confucianism. In the central, the state set up Doctors of The Classic of Filial Piety, enhancing the legal status of The Classic of Filial Piety. In the folk, The Classic of Filial Piety was advocated, and the thought of filial piety was widely publicized. The Han Dynasty took filial piety as an important concept of the governing principle politics, taking initiatives to implement the rule of filial piety. In the official selection, it established the recommendation system of inspection after the election, requiring that the recommended candidates must be filial. In order to give expression to its caring for the old, "the imperial edict of pension" was issued. In the judicial practice, the conviction and sentencing were made according to the "filial piety, which realized the legalization of filial piety.

Filial piety ethics was gradually legalized since the Han Dynasty. The concept of filial piety in the Confucian classics has been officially recognized, posing an important impact on Han Dynasty law. During the Western Han Dynasty, The Confucian scholar Dong Zhongshu quoted Spring and Autumn Annals, the Confucian classics, to hear hard cases, which was known as "the spring and autumn period and the tactic prison" in history. A lot of Confucian classics had gained official recognition in the Western Han Dynasty. If cases were heard by using The Classic of Filial Piety, conditions like this were called "the filial piety of conviction".

Case 1: "Jia had no child, picked up the abandoned boy Yi by the side of the road and raised the boy as his own. Yi committed homicide when he grew up. He told Jia the crime, and Jia hid Yi. Question: what responsibility should Jia shoulder?" Dong Zhongshu said: "Jia had no child, but he tried hard to raise Yi. Though Yi was not his own son, how can others know this fact easily. It was said in Book of Songs "there are adoption problems between insects." According to Spring and Autumn Annals: The father should hide the crime for his son, so there is an excuse for Jia's hide of his son's crime and he should not be imposed "collective punishment". (Du You, 1992) In this case, Dong Zhongshu applied the "filial piety" ideology to interpret the Confucian thought of light punishment. The "filial piety" ideology took human nature into consideration, emphasizing the reasonability of relationship between father and son. Under the guidance of this principle, the rule of law can make appropriate changes to the "filial piety".

Case 2: Jia's father Yi had a conflict with Bing because of disagreement, consequently Bing stabbed at Yi. Jia intended to hit Bing with bamboo pole but hurt Yi mistakenly. What punishment should be imposed on Jia? Someone said: "Jia should be beheaded as he hit his father." But Dong Zhongshu said: "I think the father-son relationship is the closest. On hearing that father was caught in a fight with other people, everyone as son will feel worried. Jia must have come to relieve his father by hitting Bing with bamboo pole, so absolutely he did not mean to hurt his father. There is record in Spring and Autumn Annals: Xuzhi's father was sick, so he brought medicine to his father. But because the medicine was not suitable for the disease, his father died. Xuzhi should be sentenced to death according to the law though he was not intentional. However, Spring and Autumn Annals waive Xuzhi's penalty in consideration of his real intent and filial piety. In the case of Jia, Jia's behavior was not beating father, which was the prescript of the law, so he should not be charged of beating his father. (Li Fang, 1959) Dong Zhongshu considered the case generally with the aid of filial piety in the inference of the case. Deciding the case from the doer's subjective motivation is quite reasonable.

Case 3: Jia has a son named Yi, but gave his son to Bing. Then Yi grew up, but it was Bing who raised him. Yi angrily hit Jia twenty with cane because of Jia's improper words, saying that Bing was his son. Jia thought that essentially Bing was his son, in great anger he sued to the county magistrate. Dong Zhongshu settled the case, saying that Jia's relationship with Yi had broken off as he gave Yi to Bing and did not raise Yi though Jia had gave birth to Yi. Therefore, Yi should not be sentenced despite the fact that he as a son had hit his father. (Du, 1992) The focus of this case was the cognizance of father-son relationship. In the view of Dong Zhonghshu, those who gave birth to child but did not raise him were not fit to be called father. The comprehensiveness of the case should be taken into consideration while introducing filial piety into crime. The meaning of filial piety is extensive and is a two-way street. Children should be filial piety to parents, and similarly parents should also fulfill the obligation of child support, only in this way can they be real parents.

Case 4: during the year of Jianan ruled by Emperor Xian in Donghan Dynasty, there were less farm cattle because of wars, so the law regulated that the people who killed the cattle should be sentenced to death. At that time, there was someone who sacrificed the cattle for God's spirit when his father died, as a result, he was 
sentenced to death according to the Lvling law. When the news was spread to QiaoChen who was the western governor of city Wei, he asked petition for mercy for the government (Sanguozhi.Weishu). The final decision showed two historic evidences: the first one is that filial piety had been a key factor in conviction which had been verified officially; the second one is that filial piety had been deeply rooted among the people both in people and authority.

\subsection{The Classic of Filial Piety in Tang Song Yuan Ming and Qing Dynasties}

The Confucianization of law had been completed formally since the Tang Dynasty, and the Confucian thought of filial piety was carried out overall at the national level. Comments on Laws of Tang Empire completed the Confucianization of law officially, which realized the combination of the propriety and law. The penalty for violation of filial piety is more specification in Comments on Laws of Tang Empire, implementing the concept of filial piety's full penetration of the law. Comments on Laws of Tang Empire made the purpose and main theme clear from the very beginning: Courtesy is the foundation of penalty and civilized intercourse; penalty was for political purposes. This view embodied the thought of "Virtue dominates while punishment subordinates". Starting from this point, the Tang Law put filial piety first, implementing the idea of ruling the country by filial piety comprehensively from the emperor to the nobles. Secondly, the Tang Law guaranteed the realization of filial piety content in an all-round way with normative law, relating to five aspects of living, support, illness, bereavement, sacrifice. Finally, the Tang Dynasty imposed harsh punishment on crimes of being unfilial with stern criminal law. In the Tang Dynasty, being unfilial was one of the ten grave crimes, and the doer would be severely punished by law. The case in Tang Dynasty is as follows: During the time of Wuzetian in Tang Dynasty, there was a man named Yuanqing Zhao, whose father was killed by the governor of county, Shiyun Zhao who was promoted to be higher position. In order to avenge his father, Yuanqing Zhao changed his name and killed Shiyun Zhao. As to this case, there were many arguments on it. Someone hold that Yuanqing Zhao should be forgiven due to his filial piety. However, Ziang Chen suggested another way of judgment, which meant Yuanqing Zhao should be sentenced to death according to the national law and he should be well buried with a good tombstone due to his filial piety. Ziang Chen was supported widely by public (Wenuanzhong. Ziang Chenzhuang). This case showed that filial piety has been paid more attention in Tang Dynasty than Han Dynasty, adjusting the balance between law and custom. On one hand, it upheld the majesty of law; on the other hand, it took the criminal's filial piety into consideration after the final sentence and carried forward filial piety.

Rulers in the early Tang Dynasty gave full respect for Confucianism, Buddhism, Taoism. Emperor Xuanzong of the Tang Dynasty established the strategy of governing the country by filial in order to reconstruct social order and actively promoted the wide spread of the thought of The Classic of Filial Piety in the period of his reign. On the one hand, Xuanzong noted The Classic of Filial Piety himself, which reflected the concept that the nation valued this; on the other hand, he took The Classic of Filial Piety as a compulsory subject in the imperial examinations of selecting officials. Song Taizu summed up the historical lessons of social unrest at the end of Tang Dynasty and advocated filial piety actively so as to consolidate the regime. In this time, The Classic of Filial Piety was wide spread. In the Ming Dynasty, Ming Taizu Zhu Yuanzhang made himself an example, promoting the filial piety actively. The position of The Classic of Filial Piety was enhanced in the imperial examination in the reign of Ming Taizu. Qing, as a minority regime, accepted Confucianism on its own initiative and leant the Han culture as it entered Shanhai Pass. Emperors of the Qing Dynasty paid special attention to The Classic of Filial Piety, several successive emperors annotated The Classic of Filial Piety themselves. The role of filial piety played on the folks' loyal to the king was actively pushed by Emperors of the Qing Dynasty. The Qing Dynasty applied filial piety to govern the country and strengthened the crime punishment of violation of filial piety.

\section{The Spread of the Classic of Filial Piety and Its Impact on the Surrounding Culture}

Civilization in the Tang Dynasty was becoming more and more open and inclusive with the national strength of Tang Dynasty in the early age became powerful. Comments on Laws of Tang Empire, for instance, stipulated: "foreigners who commit crimes should be tried according to their native law." The openness of the Tang Dynasty's culture was reflected in the breadth and frequency of cultural exchange. There was a time when rulers of the Tang Dynasty encouraged foreign students to learn in the Tang. The Tang Dynasty had a tolerant attitude towards foreign students and provided them with sufficient space for development. As for the educational equality, foreign students' fees of daily life shall be borne by the Tang government. On the educational content, the Confucian ethics thought was implemented throughout, and the Confucian classics like Analects of Confucius and The Great Learning were main teaching in the curriculum design. The Tang Dynasty implemented more care policy in the imperial examinations in order to better attract foreign students, and set up "Bin Gongke" to encourage foreign students to participate in the imperial examinations. The Classic of Filial 
Piety, analects of Confucius, The Great Learning and so on would become compulsory study of bibliography since the Confucian classics were major contents of the imperial examination. Orientation of the examination contents strengthened foreign students' cultural identity and deepened their understanding of Chinese traditional culture like The Classic of Filial Piety. At the same time, the officials of international students were subjected to the influence of the Tang Law in the selection and assessment of officials.

There was a time when international students were an important medium to the spread of Confucian culture, which had a profound effect on North Korea, Japanese, and Vietnamese. "The Confucian cultural circle" and "Chinese cultural circle", which were talked about in history, were roughly formed during this period.

\subsection{The Spread of Filial Piety in the Korean Peninsula}

Many factors such as geography, history and culture had contributed to the wide spread of The Classic of Filial Piety and the thought of filial piety in the Korean Peninsula. Geographically, the Korean Peninsula is closely linked with the Tang Dynasty frontier, which was a geographical advantage of nature. In communication, wars between the two parties, in turn, promoted the frequency of the communication. Government of the Tang Dynasty extensively absorbed the Xinluo students to study in Tang, and provided them with opportunities for official positions. Moreover, the government also selected foreign students for official appointments in the imperial examinations. Since The Classic of Filial Piety was included in scientific examination, it was no doubt that the foreign students' thought of Confucianism would be greatly improved, and the thought of filial piety would spread when they came back to their countries. The powerful national strength of the Tang Dynasty and cultural prosperity in turn stimulated Xinluo's "adjacent to the teacher". In 682 AD, Xinluo's God King Wen studied the Tang system, establishing Ancient Chinese Literature Search Museum in Central, educating the children of the nobility with Confucian classics. In curriculum design, he made The Classic of Filial Piety a compulsory subject so as to improve students' accomplishment of Confucianism. The smooth spread of Confucianism in the Korean peninsula was related not only to frequent exchanges between the two sides, but also to the characteristics of the family method of the North Korean nation itself. Traditional North Korean society's politics, economy and family structure were very similar to the Han and Tang Dynasties. On the one hand, the North Korean society had a special affection for the blood based family relationships; on the other hand, the basis of family attached to a lot of political and economic interests. Traditionally, ancestry-conception prevailed in North Korean, which was similar to the Nine-rank system of selecting officials in Chinese Wei and Jin Dynasties. In the caste system, imperial examinations quota was monopolized by those who were born in good family relying on good educational condition, which in some sense made social class elitist. The elite social structure made the ruler have enough strength to spread Confucianism and further consolidate its social status. Doubtlessly, the establishment of Confucianism's dominant position in North Korea had experienced a gradual process. Confucianism enjoyed religious status in North Korea mainly because people of insight tried to abolish corruption of aristocratic and monks and replace it with Confucian ethics and political philosophy during a time of dynasties succession, especially in the time when the Joseon Dynasty was established. When North Korea was in the reign of Yingzong, "Filial Piety" Copy Solution of Primary School, which was representative of Confucian Ethics, was published officially so as to implement Confucian concept of ethics education on the Korean Peninsula. A series of initiatives took by the North Korean royal had promoted filial piety and Confucianism becoming the mainstream ideology of the society in North Korea.

\subsection{The Influence of Traditional Chinese Legal Culture of Obedience on Japan}

In the 9th century, many Chinese cultural ancient books were imported into Japan, enriching Japan's cultural connotation. Among the books, Confucian classics, the wide spread of The Analects, Mencius, and The Classic of Filial Piety tremendously shocked Japanese circle of thinks. Before Meiji restoration, Japanese culture has been deeply influenced by Chinese Confucian culture, especially in Tang Dynasty. In the 12th year of Empress Suiko period (604A.D.), the Seventeen-article Constitution was proclaimed, whose first item said, "Everyone has a party or something like it. Therefore, he will either oppose to his monarch or father or oppose to his neighborhood". This item reflected that the thought of obedience has been preliminarily admitted by Japan's authority. Because this period belongs to Sui Dynasty in Chinese history, we can get the conclusion that the spread of the thought of obedience in Japan has had a long history.

Seeing from the exchange between China and Japan, we can see that the phenomenon that Japanese students went to China for study dated back to Sui Dynasty at the earliest and peaked in Tang Dynasty with the booming of Tang's culture. In Tang Dynasty, the cultural exchange between China and Japan presented new characteristics. First, the channel of exchange widened in that both official and folk channel were equally emphasized and there were official envoy dispatched to the Tang Dynasty as well as folk overseas students. In 
the flourishing period of Tang Dynasty, the size of envoy dispatched to the Tang Dynasty became larger, ranging from 500 or 600 people at most to 200 or 300 people at least. Second, the exchange between China and Japan became bidirectional. Jianzhen Crossed the Ocean to Japan to spread Buddhist culture is one of the best examples. Finally, the extent of exchange broke through from culture to the study of legal system. Take the legalization of obedience ethic for example, Japanese government then tried hard to imitate Tang Dynasty in realizing the legalization of obedience ethic. At that time, Tang Dynasty proclaimed the order of providing for the aged for many times based on combining with the law and etiquette. Later, Japan added "filial piety" to the order of providing for the aged according to its national conditions. "In terms of Japan's Yoro-ritsuryo, it is completely the same with that of Tang. Basically speaking, many of its items totally imitated the original text of Tang's laws and decrees."

The spread means of The Classic of Filial Piety in China and Japan are strikingly similar. The government in the period of Emperor Xuanzong strengthened the spread of The Classic of Filial Piety, ordering every people collect The Classic of Filial Piety for study and observance. At about the same time, the queen of Obedience and Humility learned Tang Dynasty in ordering people collect The Classic of Filial Piety for reading and remembering. After wide spread of the thought of obedience, Japan formed a different social moral concept based on its indigenous culture. Chinese governor strived to realize the integration of family and country, the combination of loyalty and obedience, and the transmission of obedience to loyalty, requiring his subjects extend their obedience to family to their loyalty to the country. But in the level of loyalty, he didn't excessively limit obedience. In Japan, the governor ordered the subjects to "transmit obedience to loyalty". However, he has rigid requirement on loyalty, thinking that loyalty should become the supreme moral code to which all the subjects obey. The governor emphasized absolute obedience of the low position to the high position, aiming at the consolidation of imperial power.

\subsection{The Influence of the Thought of Obedience on Vietnam}

The spread of the thought of obedience in Vietnam closely link to the spread of Confucianism in it. Accompanied by the southward extension of Chinese territory, the communication between China and Vietnam became increasingly frequent. When central plains dynasty governed Nanyue area, orthodox Confucianism thought was strongly implemented by local authority. For its relatively liberal characters, it was gradually accepted by local people. After Vietnam realized independence and built country, the thought of obedience and loyalty was initiatively popularized by the governor for it catered to governor's concept of governing. Under that background, obedience culture was widely spread. The concept that "obedience is the highest in hundreds of virtues" was approved by the people universally.

\section{Conclusion}

In the long history of human culture, Chinese culture has deeply influenced the surrounding countries. Traditional Confucianism culture of which filial piety is representative played an important role in the spread of culture. The appearance of filial piety symbolizing the progress of civilization while the composition of The Classic of Filial Piety symbolized the theorization and systematization of obedience thought. In view of the death of Qin Dynasty because of tyranny, the governor of each dynasty advocated governing the country by means of obedience and required the people to transmit their obedience to family to loyalty to governor. To achieve the goal, the governor not only was highly interested in explanation and spread of The Classic of Filial Piety, but also required people to collect and remember it. Coordinating with the goal of governing the country by means of obedience, legalization of obedience thought gradually established. The obedience thought after legalization was approved by the country step by step with the help of compulsion power of criminal law. Echoing with domestic spread of obedience thought and accompanying by the booming of China's national power as well as strengthening of cultural exchange among different countries, filial piety culture spread far as to other Asian countries. Especially in Tang Dynasty, The Classic of Filial Piety and obedience thought accelerated to spread to Japan, Korean peninsula, Vietnam and so on, promoting their cultural progress. The surrounding countries accepted Chinese filial piety culture and at the same time made it localization further on the basis of their national conditions.

\section{References}

Zhang, J. F. (2009). The tradition and Modern Transition of Chinese Law. Beijing: Law Press.

Du, Y. (1992). Tong Dian. Beijing: Zhonghua Book Company.

Hegel. (2006). History Philosophy (p. 165). Translated by Wang Zaoshi. Shanghai: Shanghai Book Store.

Li, F. (1959). Taiping Yulan (Vol. 640, p. 2482), Taibei: Xinxing Book Company. 
Russell. (1996). China problem (p. 30). Translated by Qin. Shanghai: Xuelin Press.

Zheng, X. W. (2004). Tang Dynasty lï-ling law System Study (p. 25), Beijing: Beijing University Press.

Li, W. L., \&Du, Y. K. (2012). RuJia Xiao Ethics and Han-Tang Dynasty Law (p. 321), Beijing: Law Press.

Wang, X. Q., \& Da, T. X. (1996). Chinese-Japanese Culture Communication History Summary (p. 117). History Volume, Hangzhou: Zhejiang People Press.

\section{Copyrights}

Copyright for this article is retained by the author(s), with first publication rights granted to the journal.

This is an open-access article distributed under the terms and conditions of the Creative Commons Attribution license (http://creativecommons.org/licenses/by/3.0/). 